\title{
Cooperativas de catadores e os desafios para a autogestão
}

\section{Gustavo Diego Magno ${ }^{1,}{ }^{,}$, Adriani Izabel de Souza Moraes ${ }^{2}$, Tatiane Bonametti Veiga ${ }^{3}$ e Sílvia Carla da Silva André Uehara ${ }^{4}$}

${ }^{1}$ Universidade Federal de São Carlos. Departamento de Enfermagem. Curso de Graduação em Enfermagem. Rodovia Washington Luís, km 235. São Carlos-SP, Brasil (CEP 13565-905). E-mail: gustavomagno@estudante.ufscar.br.

${ }^{2}$ Universidade Federal de São Carlos. Departamento de Enfermagem. Curso de Mestrado em Enfermagem. Rodovia Washington Luís, km 235. São Carlos-SP, Brasil (CEP 13565-905).

${ }^{3}$ Universidade Estadual do Centro-Oeste do Paraná. Departamento de Engenharia Ambiental. Rodovia PR 153, km 7. Irati-PR, Brasil (CEP 84500-000).

${ }^{4}$ Universidade Federal de São Carlos. Departamento de Enfermagem. Rodovia Washington Luís, km 235. São Carlos-SP, Brasil (CEP 13565-905).

Resumo. As cooperativas de catadores são as únicas organizações responsáveis pela coleta seletiva em diversos municípios brasileiros e asseguram maior estabilidade de renda e proteção social em comparação ao trabalho de catadores autônomos. Este estudo teve como objetivo analisar as práticas de cooperativismo e autogestão em um empreendimento de catadores de materiais recicláveis e seus desafios e contribuições para a geração de renda e trabalho dignos. Trata-se de um estudo de caso do tipo exploratório-descritivo realizado com 27 catadores de uma cooperativa de materiais recicláveis do Município de São Carlos, Estado de São Paulo, Brasil. Os dados foram coletados por meio de observação participante e entrevista estruturada. Constatou-se que $81,5 \%$ dos catadores eram do sexo feminino, $70,3 \%$ não concluíram o ensino fundamental e a renda média era de $\mathrm{R} \$ 849,26$. Observou-se predominância na concepção de que a cooperativa deve ser orientada pela igualdade e união. Entretanto, identificou-se a centralização do processo decisório nos cargos administrativos, separação entre gestão e produção, e pouco ou nenhum conhecimento sobre como se dá a distribuição dos ganhos. Apesar da cooperativa de catadores promover renda, trabalho e segurança social, não garante renda suficiente para retirar todos catadores da insegurança alimentar. A falta de capacitação dos catadores sobre autogestão e para o trabalho administrativo dificulta um melhor desempenho da cooperativa, fazendo-se necessário o apoio de outras instituições para a qualificação do trabalho.

Palavras-chave: Catador de material reciclável; Cooperativa;
Recebido

$11 / 05 / 2021$

Aceito

$09 / 07 / 2021$

Disponível on line $11 / 07 / 2021$

Publicado

$31 / 08 / 2021$

Acesso aberto

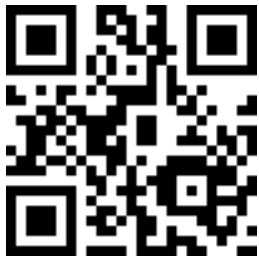

0000-0003-3656-9170 Gustavo Diego Magno

ISSN 2359-1412/RBGAS-2021-0046/2021/8/19/12/831

Rev. Bras. Gest. Amb. Sustent.

http://revista.ecogestaobrasil.net 
Gerenciamento de resíduos sólidos; Autogestão; Economia solidária.

\begin{abstract}
Waste pickers cooperatives and the challenges for self-management. In several Brazilian municipalities the waste pickers cooperatives are the only organizations responsible for selective collection and ensure greater income stability and social protection compared to the work of independent waste pickers. This study aimed to analyze the practices of cooperativism and self-management in a waste pickers' cooperative and their challenges and contributions to the generation of income and decent work. This is an exploratory-descriptive case study conducted with 27 waste pickers from a cooperative of recyclable material in the Municipality of São Carlos, State of São Paulo, Brazil. The data were collected through participant observation and structured interviews. It was found that $81.5 \%$ of the collectors were female, $70.3 \%$ had not completed elementary school, and the average income was $\mathrm{R} \$ 849.26$. There was a predominance of the concept that the cooperative should be guided by equality and union. However, it was observed the centralization of the decision-making process in administrative positions, separation between management and production, and little or no knowledge of how the distribution of gains takes place. The cooperative promotes income, work and social security, but it does not guarantee sufficient income to remove all collectors from food insecurity. The lack of training of the collectors on selfmanagement and administrative work hinders a better performance of the cooperative, making the support of other institutions necessary for the qualification of the work.
\end{abstract}

Keywords: Waste pickers; Cooperative; Waste management; Selfmanagement; Solidarity economy.
(1) 0000-0001-6619-8791

Adriani Izabel de Souza Moraes

() 0000-0002-6919-4013

Tatiane Bonametti Veiga

D) 0000-0002-0236-5025

Sílvia Carla da Silva

André Uehara

\section{Introdução}

A geração de resíduos sólidos no mundo vem aumentando consideravelmente nas últimas décadas em razão do aumento da população, da urbanização e do crescimento econômico, que, por sua vez, culminaram no aumento da produção, consumo e descarte de resíduos sólidos (Singh et al., 2014). No Brasil, em 2019, foram geradas 79 milhões de toneladas de resíduos sólidos urbanos (RSU), sendo que 40,5\% foram dispostos em aterros controlados e lixões, pondo em risco a saúde humana e ambiental (ABRELPE, 2020).

A coleta seletiva nos municípios brasileiros é realizada pela prefeitura, por empresas contratadas pela prefeitura ou por catadores de materiais recicláveis, que atuam de forma autônoma ou organizados em cooperativas e associações. Em 2018, 50\% dos municípios com coleta seletiva tinham cooperativas de catadores de materiais recicláveis como agentes da coleta seletiva municipal (CEMPRE, 2019). Estimativas mostram que em 2012 havia entre $400 \mathrm{mil}$ a $600 \mathrm{mil}$ pessoas trabalhando como catador no Brasil, das quais 40 mil a 60 mil participavam ou já tinham participado de alguma associação ou cooperativa de catadores (IPEA, 2013), sendo que, em 2008, o número dessas organizações era de 1.175 cooperativas, aproximadamente (IBGE, 2010). 
As cooperativas de catadores de materiais recicláveis surgiram no Brasil na década de 1980, época em que o país possuía um elevado número de desempregados e reduzidas possibilidades de entrada no mercado de emprego formal. Assim, essa nova forma de organização permitiu aos catadores a busca pelo reconhecimento social e de políticas públicas que pudessem melhorar suas condições de trabalho e qualidade de vida, alinhados às práticas de autogestão (Medeiros e Macêdo, 2006).

Muitas organizações de catadores passaram a se organizar como empreendimento de economia solidária. Singer (2002) empregou o termo "economia solidária" para descrever a organização com práticas autogestionárias entre pessoas sem acesso ao trabalho formal, geralmente com baixa ou nenhuma formação educacional, e que se unem para conquistar sua renda e lutar contra a marginalização. Essas novas relações produtivas, dentro de uma perspectiva de economia sustentável e solidária, se contrapõem à competitividade do sistema capitalista entre empresas e dentro das empresas, como transição de modo de produção e em combate às desigualdades sociais.

Quando comparadas as condições de trabalho e vida de catadores autônomos e catadores organizados em cooperativas, percebe-se que os autônomos se encontram em maior situação de vulnerabilidade social, em piores condições de trabalho e expostos a maiores riscos à saúde. Por outro lado, em alguns casos, os catadores cooperados contribuem para a previdência social e possuem certa proteção social, carga de trabalho menor, podem acumular material no galpão para vender a melhores preços e possuem participação nas decisões da cooperativa (Gutberlet et al., 2017; Navarrete-Hernandez; Navarrete-Hernandez, 2018; Yang et al., 2018).

Dessa forma, as cooperativas de catadores, enquanto empreendimentos autogestionários, possibilitam a geração de trabalho e renda ao promoverem a posse dos meios de produção pelos catadores e redistribuição dos ganhos, alinhados à participação dos membros no processo decisório (Tauile e Rodrigues, 2004; Faria, 2017; Gutberlet et al., 2017). Em contrapartida, há muitos outros empreendimentos, principalmente de sucateiros, que exploram o trabalho dos catadores, pagando baixos valores pelo peso do material coletado ou triado, dificilmente garantindo sua sobrevivência (Medeiros e Macêdo, 2006; Sterchile e Batista, 2011; Lordello, 2014). Assim, as cooperativas e associações com características de autogestão são as únicas alternativas para os catadores enfrentarem um meio altamente exploratório.

A cadeia produtiva de reciclagem tem sua base composta pelos catadores, que são os principais agentes da reciclagem e, no entanto, os que obtêm menor lucro. Intermediando o comércio de material reciclável entre catadores e indústria de reciclagem, estão os atravessadores ou sucateiros, que determinam o valor de compra de cada tipo de material reciclável vendido pelos catadores. Em razão do número reduzido de compradores, os catadores não conseguem negociar o preço de venda dos recicláveis e, tampouco, coletar individualmente a quantidade necessária para vender diretamente às indústrias (Arantes e Borges, 2013).

Não diferente dos catadores autônomos, as cooperativas de catadores também encontram barreiras para comercializar diretamente com as indústrias, sendo algumas das razões as exigências em relação às características do material, quantidade, distância das indústrias e falta de meios para realizar a entrega do material. Assim, os atravessadores se tornam principais compradores das cooperativas e estabelecem o preço de cada material de acordo com a cor, pureza e formato, entre outras características (Campos, 2014; Demajorovic et al., 2014).

Nesse contexto, em 2010, foi publicada a Política Nacional de Resíduos Sólidos (PNRS) que prioriza o acesso a recursos da União àqueles municípios que, na elaboração do Plano Municipal de Gestão Integrada de Resíduos Sólidos (PMGIRS), implementarem a coleta seletiva com a participação de cooperativas ou outras formas de associação de catadores de materiais reutilizáveis e recicláveis. A PNRS também sugere que o poder 
público priorize às cooperativas de catadores o acesso a medidas indutoras e linhas de financiamento para atender à implantação de infraestrutura física e aquisição de equipamentos (Brasil, 2010). Embora, o que se observa em muitos municípios é o favorecimento a empresas privadas enquanto cooperativas de catadores passam por dificuldades de funcionamento, além de ser possível encontrar gestores municipais que promovem falsas cooperativas, que subvertem os princípios cooperativistas e promovem a exploração dos catadores (Sterchile e Batista, 2011).

Desse modo, as cooperativas de catadores se encontram em um contexto de conflitos de interesses políticos e econômicos. Em termos econômicos, estima-se que os resíduos reciclados no país gerem benefícios entre $\mathrm{R} \$ 2,4$ e $\mathrm{R} \$ 5,7$ bilhões anuais, e caso os resíduos sólidos recicláveis encaminhados a aterros e lixões fossem reciclados, poderia se gerar um benefício econômico de $\mathrm{R} \$ 13$ bilhões anuais (valores corrigidos pelo IGP-M de julho de 2019) (IPEA, 2010). Porém, segundo relatório do IPEA (2012), a renda média de catadores organizados em cooperativas e associações no país, em 2010, encontrava-se em um intervalo entre $R \$ 420,00$ e $R \$ 520,00$, ou seja, próximo a um salário mínimo para a época ( $\mathrm{R} \$ 510,00)$. A renda destes trabalhadores é, portanto, baixa quando analisadas as contribuições que as cooperativas de catadores geram à economia e ao meio ambiente, além dos catadores terem que se submeter a longas jornadas de trabalho exaustivo e insalubre para obter uma renda suficiente para subsistência de sua família. Assim, a cadeia produtiva de reciclagem é extremamente desigual e o lucro acaba se concentrando, principalmente, nas grandes indústrias.

Alguns estudos realizados em organizações de catadores de materiais recicláveis demonstram precariedade nas condições de trabalho alinhados ao baixo apoio do governo local e à baixa capacitação dos catadores (Gutberlet et al., 2017; Coelho et al., 2018; Moreira et al., 2019). Além disso, outros estudos apontam a dificuldade das cooperativas de catadores em comercializar diretamente com fábricas de reciclagem e negociar preços de venda, apresentando, em geral, baixos ganhos (Dias, 2016; Dutra et al., 2018; Fidelis e Colmenero, 2018).

As cooperativas de catadores, enquanto empreendimentos solidários, se encontram em um dilema entre ser mais produtiva e rentável diante de um mercado competitivo e desigual, ao mesmo tempo em que devem se manter orientadas pelos valores da economia solidária e exercendo práticas de autogestão, sem se confundirem com as organizações capitalistas (Lima, 2010). Frente a conflitos de interesses políticoeconômicos, as cooperativas de catadores precisam garantir renda e trabalho dignos aos seus membros e atuarem com foco em bons resultados. Diante dessas considerações, a questão de pesquisa que buscamos elucidar foi "Quais ações podem ser tomadas para colaborar com os desafios que comprometem as práticas do cooperativismo e autogestão em cooperativas de catadores?"

Tendo em vista a contribuição dos catadores para a reinserção do material reciclável na cadeia produtiva, acarretando na minimização do impacto ambiental e dos custos causados pela disposição final de RSU em aterros e lixões, além das cooperativas de catadores como meio para a conquista de renda digna, este estudo teve como objetivo analisar as práticas do cooperativismo e da autogestão em uma cooperativa de catadores e suas contribuições e desafios para a geração de renda e trabalho dignos, apresentando proposições para o aprimoramento da atuação dos catadores para a gestão de cooperativas.

\section{Material e Métodos}

A coleta de dados foi realizada durante os meses de junho a julho de 2019 em duas etapas, a observação participante e a entrevista estruturada. 
A observação participante teve o intuito de aproximar o pesquisador dos participantes da pesquisa em seu cenário de atuação para compreensão de sua realidade (Queiroz et al., 2007). Durante a observação participante foram observados a rotina e as condições de trabalho dos catadores e suas relações interpessoais. A observação participante foi realizada em três situações: a) durante a realização da coleta de material reciclável nas ruas (cinco dias); b) triagem, prensagem, estocagem e comercialização dos resíduos no barracão (20 dias); c) triagem nos quatro ecopontos ativos da cidade (três dias).

Para a realização da entrevista foi utilizado um roteiro estruturado adaptado de Bispo (2013), o qual foi dividido em três seções: a) perfil sociodemográfico (sexo, idade, escolaridade, estado civil, número de filhos, situação de moradia e renda); b) satisfação com a renda, organização e administração da cooperativa; c) autogestão e capacitação para o trabalho (conhecimento sobre temas administrativos e financeiros da cooperativa e dos processos de trabalho).

A população do estudo foi composta por catadores da cooperativa e como critério de inclusão definiu-se: estar vinculado à cooperativa como catador há pelo menos três meses e estar presente durante o período de coleta de dados. Dos 42 trabalhadores da cooperativa, quatro $(9,5 \%)$ trabalhavam apenas como motoristas, portanto, apenas 38 eram catadores propriamente dito. No período da coleta de dados, dos 38 catadores, quatro $(10,5 \%)$ estavam afastados ou de licença e três $(7,9 \%)$ possuíam menos de três meses de trabalho. Dessa forma, $31(81,6 \%)$ catadores cooperados atendiam aos critérios de inclusão do estudo. Ainda, quatro (12,9\%) dos 31 cooperados optaram por não participar, portanto, a população do estudo foi composta por 27 participantes, ou seja, 87,1\% dos 31 catadores dentro dos critérios de participação.

As variáveis relacionadas aos conhecimentos e práticas de autogestão foram analisadas tendo o $n$ definido pelo total de respostas, uma vez que havia mais de uma opção de escolha, e não de acordo com o total de participantes.

Os dados obtidos das entrevistas foram duplamente digitados em um banco de dados estruturado no software Microsoft Excel ${ }^{\circledR}$ e analisados por meio da estatística descritiva.

A pesquisa foi aprovada pelo Comitê de Ética em Pesquisa (CEP) da Universidade Federal de São Carlos (UFSCar), sob o Certificado de Apresentação para Apreciação Ética (CAAE) no 00489418.8.0000.5504/2019. Todos participantes assinaram o Termo de Consentimento Livre e Esclarecido.

\section{Resultados e discussão}

\section{Realidade do trabalho em uma cooperativa de catadores}

No Município de São Carlos, no Estado de São Paulo, atores da sociedade civil formaram o Fórum Comunitário do Lixo, em 1999, para lutar pela gestão eficaz e eficiente dos RSU no município. Em 2002, foi criado o Programa de Coleta Seletiva na cidade e houve a formação e incorporação de três cooperativas de catadores (Coopervida, Cooletiva e Ecoativa), compostas por 46 catadores que, até então, trabalhavam no aterro de São Carlos. Essa iniciativa atendeu às demandas de grupos da sociedade civil que buscavam um modelo mais eficiente de gestão ambiental, combinado com a geração de trabalho e renda a partir da inclusão de catadores (Santos et al., 2018).

No início de 2010, as três cooperativas se unificaram em busca do aumento da produtividade e da regularização. A cooperativa resultante dessa unificação adotou os princípios da economia solidária e conseguiu um contrato com a prefeitura para realizar a coleta seletiva na cidade e em seis ecopontos (pontos de entrega voluntária). Não obstante, formou-se uma rede de cooperativas de catadores de materiais recicláveis da região central do estado de São Paulo, denominada Rede Anastácia. Essa rede foi criada 
com o objetivo de fortalecer os empreendimentos de materiais recicláveis organizados na perspectiva da economia solidária e compartilhar informações sobre compra de insumos, venda de material reciclável e aquisição de novas tecnologias de coleta e de produção (Savio e Teixeira, 2016; Santos et al., 2018).

0 trabalho na cooperativa ocorre de segunda à sexta-feira, das $8 \mathrm{~h}$ às $17 \mathrm{~h}$, sendo que de segunda a quarta-feira, das $9 \mathrm{~h}$ às $16 \mathrm{~h}$, a coleta é realizada no sistema porta-a-porta, com trajetos definidos para atender diferentes bairros em cada dia. Nas quintas e sextasfeiras, os cooperados do sexo masculino saem em quatro caminhões para realizar a coleta em locais com concentração de grande volume de materiais recicláveis previamente separados, como condomínios, universidades e fábricas; e as cooperadas permanecem no barracão realizando a triagem do material coletado.

Para realizar a coleta, os catadores ocupam as traseiras dos caminhões, sendo de seis a oito mulheres e quatro homens. Ao chegar nas áreas de coleta, formam-se duplas de mulheres que seguem a pé por uma determinada rota. 0 material reciclável é acondicionado em sacos de ráfia $(b a g)$ e o caminhão da cooperativa circula pelas ruas com os homens para recolher os bags cheios, além de outros objetos pesados descartados pelos moradores, como geladeira e máquina de lavar.

Após a coleta, os bags são empilhados no barracão para, posteriormente, ser triado o material coletado. Na triagem, uma mesa se destina exclusivamente a retirar rótulos de plástico duro e separá-los por cor. As outras duas mesas recebem todo o material coletado, para proceder a separação do PET, garrafas de vidro, papelão, papel branco, papel misto, embalagem longa vida, isopor, metal, eletrônicos, entre outros. As cooperadas trabalham em pé e inclinadas sobre as três mesas de triagem, durante todo o dia. Após ser triado, o material é prensado por um ou dois homens em uma prensa enfardadeira vertical. Esse processo é considerado o mais difícil, pois exige muito esforço físico devido ao peso dos fardos, que chegam a pesar $150 \mathrm{~kg}$. Os fardos são amontoados e os mais pesados são retirados por uma garra sucateira acoplada ao caminhão dos compradores.

Os processos de coleta, triagem e prensagem consistem, portanto, em atividades de prolongada permanência em pé, alto esforço físico para erguer ou arrastar grandes cargas de peso, poucas pausas para descanso e movimentos repetitivos. Essas características dos processos de trabalho também são observadas em outras cooperativas de catadores e evidenciam os riscos de adoecimento e lesão da atividade de catador (Araújo e Sato, 2018; Asante et al., 2019; Cruvinel et al., 2019). Nesse cenário, as catadoras preferem realizar a coleta do que a triagem, uma vez que o trabalho de coleta permite algumas pausas, estar ao ar livre e interagir com os moradores, além de, muitas vezes, ganharem panelas, eletrodomésticos, brinquedos e roupas dos moradores.

A cooperativa também realiza a triagem e retirada de materiais recicláveis descartados em quatro ecopontos ativos de São Carlos. Em cada ecoponto trabalha um cooperado, responsável pela triagem e por auxiliar a população quanto ao descarte adequado dos materiais. Esses locais recebem, principalmente, pequenos volumes de resíduos da construção civil, galhos e troncos de árvores, móveis, eletrônicos e pneus. A retirada dos resíduos que não são recicláveis é responsabilidade da prefeitura, no entanto, observou-se durante as visitas acúmulo de resíduos dentro dos ecopontos e nas vias no entorno. Os moradores da região e os cooperados queixam-se do risco de proliferação de pragas e doenças, como dengue, além da dificuldade de transitar pela rua e da poluição visual.

Destaca-se que todos os ecopontos já foram incendiados e invadidos por usuários de drogas ilícitas por pelo menos uma vez. Além disso, os catadores autônomos furtam os materiais recicláveis, tornando os ecopontos pouco produtivos, sendo que dois destes locais são totalmente improdutivos, se convertendo em lixões de resíduos da construção civil e restos de podas de árvores. 


\section{Perfil sociodemográfico e vulnerabilidade social}

Dos 27 participantes do estudo, 81,5\% (22) eram do sexo feminino, 29,6\% (8) com idade entre 50 e 59 anos, 25,9\% (7) referiram ter 2 filhos, 37,0\% (10) declararam estar em união estável, 70,3\% (19) não tinham concluído o ensino fundamental e 51,9\% (14) possuíam casa própria (Tabela 1). Esses achados corroboram dados de estudos anteriores que verificaram um baixo nível de escolaridade entre os catadores e uma participação acentuada de mulheres (Castilhos Junior et al., 2013; Auler et al., 2014; Teixeira, 2015; Alves et al., 2020). A presença de uma maioria feminina em cooperativas de catadores pode ser motivada pela maior segurança, por não ficarem sozinhas nas ruas, pela maior aceitação em trabalhar em grupo e o maior compartilhamento do sentido de coletividade e solidariedade em relação aos homens (Coelho et al., 2016, 2017).

Tabela 1. Perfil sociodemográfico dos catadores de uma cooperativa de materiais recicláveis do Município de São Carlos-SP, 2019.

\begin{tabular}{|c|c|c|}
\hline Variável & $\mathbf{N}$ & $\%$ \\
\hline \multicolumn{3}{|l|}{ Sexo } \\
\hline Feminino & 22 & 81,5 \\
\hline Masculino & 5 & 18,5 \\
\hline \multicolumn{3}{|l|}{ Faixa etária (anos) } \\
\hline 18 a 29 & 5 & 18,5 \\
\hline 30 a 39 & 7 & 25,9 \\
\hline 40 a 49 & 6 & 22,2 \\
\hline 50 a 59 & 8 & 29,6 \\
\hline 60 a 69 & 1 & 3,7 \\
\hline \multicolumn{3}{|l|}{ Escolaridade } \\
\hline Não alfabetizado & 1 & 3,7 \\
\hline Fundamental incompleto & 19 & 70,3 \\
\hline Fundamental completo & 1 & 3,7 \\
\hline Ensino Médio incompleto & 4 & 14,8 \\
\hline Ensino Médio completo & 2 & 7,4 \\
\hline \multicolumn{3}{|l|}{ Estado civil } \\
\hline União estável & 10 & 37,0 \\
\hline Casado & 8 & 29,6 \\
\hline Solteiro & 5 & 18,5 \\
\hline Divorciado & 2 & 7,4 \\
\hline Viúvo & 2 & 7,4 \\
\hline \multicolumn{3}{|l|}{ Número de filhos } \\
\hline 0 & 2 & 7,4 \\
\hline 1 & 3 & 11,1 \\
\hline 2 & 7 & 25,9 \\
\hline 3 & 3 & 22,2 \\
\hline 4 a 5 & 6 & 22,2 \\
\hline 6 a 7 & 2 & 7,4 \\
\hline 8 a 9 & 1 & 3,7 \\
\hline
\end{tabular}

Em relação à renda mensal familiar, 40,7\% (11) dos participantes afirmaram que é menor que um salário mínimo por mês e 37,0\% (10) relataram que a renda da família é composta unicamente pelo que provêm da atividade de catador. A renda autodeclarada pelos cooperados, obtida pelo trabalho na cooperativa, varia de $\mathrm{R} \$ 600,00$ a $\mathrm{R} \$ 1.200,00$, 
com média de $R \$ 849,26$, sendo que 74,0\% afirmaram receber entre $R \$ 601,00$ e $R \$$ 900,00. Ainda, 59,2\% (16) dos cooperados afirmaram receber algum tipo de auxílio financeiro para complementar a renda de catador, sendo que 48,1\% (13) recebem auxílio financeiro do programa de transferência de renda Bolsa Família (Tabela 2). Apesar da renda mensal referida pelos participantes ser em média inferior a um salário mínimo ( $\mathrm{R} \$$ $954,00)$, ainda é próxima ou superior ao encontrado em outros estudos em que a renda média em organizações de catadores estava entre $\mathrm{R} \$ 572,00$ e $\mathrm{R} \$$ 872,00 (Castilhos Junior et al., 2013), $R \$ 592,62$ (Teixeira, 2015) e entre $R \$ 490,00$ e $R \$ 979,50$ (Guimarães, 2017), (valores corrigidos pelo IGP-M, para julho de 2019).

A variação da renda observada nas respostas dos cooperados pode ser explicada pela instabilidade da quantidade de material coletado e vendido, além da variabilidade dos preços estabelecidos por atravessadores. Também há descontos de $11,0 \%$ sobre os rendimentos para o pagamento da previdência social, $\mathrm{R} \$ 120,00$ para o transporte fretado e $\mathrm{R} \$ 30,00$ para cada dia de falta sem atestado médico. Por outro lado, os cooperados que trabalham nos ecopontos são os que afirmaram receber um maior salário, por não terem gastos com o transporte fretado, uma vez que residem próximos aos ecopontos.

Embora sinalizado como fator positivo nas cooperativas, a contribuição para a previdência social torna-se muito difícil para a maioria dos cooperados devido ao baixo rendimento mensal (Coelho et al., 2016). Diante das condições insalubres e dos riscos do trabalho de catador, a não contribuição para a previdência social gera maior vulnerabilidade socioeconômica, uma vez que inviabiliza a aposentadoria e não assegura o auxílio financeiro em caso de afastamento por doença ou acidente.

Tabela 1. Renda dos catadores de uma cooperativa de materiais recicláveis do Município de São Carlos-SP, 2019.

\begin{tabular}{|l|c|c|}
\hline Variável & N & \% \\
\hline Renda mensal da família (salários mínimos*) & & \\
\hline$<1$ & 11 & 40,7 \\
\hline $1 \mid-2$ & 10 & 37,0 \\
\hline $2 \mid-3$ & 4 & 14,8 \\
\hline $3 \mid-5$ & 2 & 7,4 \\
\hline Renda da atividade de catador (em reais) & 4 & 14,8 \\
\hline 601,00 a 700 & 10 & 37,0 \\
\hline 701,00 a 800,00 & 6 & 22,2 \\
\hline 801,00 a 900,00 & 2 & 7,4 \\
\hline 901,00 a 1000,00 & 1 & 3,7 \\
\hline 1001,00 a 1100,00 & 4 & 14,8 \\
\hline 1101,00 a 1200,00 & 12 & 44,4 \\
\hline Benefícios financeiros recebidos & 1 & 3,7 \\
\hline Bolsa Família & 2 & 7,4 \\
\hline Bolsa Família e pensão alimentícia & 1 & 3,7 \\
\hline Pensão alimentícia & 11 & 40,7 \\
\hline Cesta básica & \\
\hline Nenhum & 1 \\
\hline
\end{tabular}

*Salário mínimo equivalente a R\$954,00.

Quanto à satisfação com a renda obtida na cooperativa, 51,9\% (14) apontaram que dificilmente pagava todas as despesas mensais, como água, luz e aluguel; e 18,5\% (5) afirmaram ter dificuldades para adquirir alimentos. Esses achados corroboram o estudo de Almeida et al. (2010) onde se verificou que 33,3\% dos cooperados de uma cooperativa 
de catadores de materiais recicláveis gostariam de ter uma melhor alimentação e ter o necessário para viver e 50,0\% declararam que gostariam de receber uma melhor renda, ter trabalho mais seguro e carteira assinada. Portanto, identifica-se que o perfil dos catadores de cooperativas se enquadra em um grupo de alta vulnerabilidade socioeconômica, inclusive de risco de insegurança alimentar.

Ainda em relação à renda, estudo realizado por Porto et al. (2004) mostrou que catadores autônomos ganhavam mais do que aqueles que trabalhavam em cooperativa, ambos trabalhando no mesmo aterro controlado. Porém, para 89,0\% dos cooperados a situação atual era melhor do que ser autônomo, pois apresentava melhor condição de trabalho e maior proteção social e de saúde, além de uma menor carga horária de trabalho. Torna-se evidente que a renda não é o único fator em consideração para aqueles que optam por ingressar e permanecer em cooperativas de catadores, mas, também, as condições de trabalho e de saúde e a defesa dos direitos sociais.

Apesar das condições precárias de trabalho, ao confrontar dados da observação participante com os dados das entrevistas é possível identificar que a maioria dos cooperados entende como sendo digno o seu trabalho, pois se trata de um trabalho árduo e honesto.

Quando questionados sobre os beneficiados pela coleta e reciclagem, 40,7\% (11) dos catadores afirmaram que os empresários são os maiores beneficiados, 33,3\% (9) referiram o meio ambiente, 14,8\% (4) relataram o governo, e, 11,1\% (3) afirmaram ser a população. Ressalta-se que nenhum dos participantes indicou os catadores como os maiores beneficiados, revelando uma percepção negativa da cadeia produtiva da reciclagem, em que o catador está posicionado de forma desvalorizada, economicamente e socialmente.

\section{Conhecimentos e práticas de autogestão}

Sobre a definição de cooperativa, destacam-se as seguintes respostas: união e igualdade entre os trabalhadores, 70,0\% (21); e não souberam responder, $10,0 \%$ (3). Por outro lado, em relação à satisfação com a organização da cooperativa, destacam-se do total de respostas: administração ineficaz, 18,9\% (10); e falta de união entre os cooperados, 17,0\% (9). A concepção de que a cooperativa deve ser pautada em união e igualdade é predominante entre os catadores, entretanto, observa-se que há respostas apontando debilidade nesse aspecto. Considerando que a cooperativa, enquanto empreendimento de economia solidária, deve estar pautada na gestão democrática e igualitária (Singer, 2002), a união entre os catadores acaba por ser fomentada pelo envolvimento nas diferentes atividades da cooperativa e no processo de tomada de decisão.

Em relação à comercialização dos materiais recicláveis, para 55,6\% (15) dos participantes o material triado era vendido para atravessadores, e, 44,4\% (12) não sabiam para quem era vendido. Já sobre a quantidade de materiais coletados por mês e o seu valor de venda, 96,3\% (26) dos participantes não souberam informar. Ainda nesse sentido, destaca-se que $54,8 \%$ (17) referiram que a renda de catador na cooperativa era calculada de acordo com os dias trabalhados, e 16,1\% (5) não souberam informar como era calculada a renda obtida.

O conhecimento limitado dos cooperados sobre o funcionamento da cooperativa, inclusive sobre a forma como se dá a distribuição dos ganhos, pode ser resultado da divisão do trabalho na cooperativa entre a gestão e o processo de produção (coleta, triagem e prensagem), centrando nos cargos administrativos todo o processo de tomada de decisão e o conhecimento sobre temas financeiros da cooperativa, sem se preocupar em envolver todos os cooperados no processo decisório. Ainda nesse sentido, como aponta Souza et al. (2014), a não participação dos cooperados pode estar atrelada ao receio em criar um acirramento com seus colegas ou por acreditarem não ter capacidade para compreender os temas relativos à administração. Por essa razão, são necessárias ações 
para capacitação dos cooperados para a atuação e compartilhamento das responsabilidades em relação à gestão da cooperativa.

Para Tauile e Rodrigues (2004), muitos membros de empreendimentos solidários têm dificuldade em se ver como responsável pelo empreendimento e participante nos seus lucros e prejuízos, mantendo, assim, a visão de assalariado. Ao se colocarem como donos do empreendimento, os cooperados se tornam os principais interessados na busca por melhorar seu processo de produção e rentabilidade.

Segundo Petersen et al. (2014), a autogestão permite a construção do sentimento de protagonismo de suas próprias histórias e de vínculos afetivos entre seus semelhantes, porém, para o desenvolvimento de empreendimentos autogestionários se faz necessário o compartilhamento dos valores da autogestão e a capacitação dos membros do empreendimento para a prática desse modelo de gestão.

No que se refere à necessidade de mudanças a serem realizadas na cooperativa, destacam-se as seguintes respostas: necessidade de uma administração mais capacitada, $24,2 \%$ (8); e necessidade de dispensa de cooperados descomprometidos com o trabalho, 15,2\% (5). A administração pouco capacitada, assim como a dificuldade de alguns cooperados em trabalhar em uma lógica de relações de trabalho não capitalista são barreiras para o êxito dos empreendimentos autogestionários. Tanto a falta de capacitação técnica para a administração da cooperativa, quanto a falta de união entre os cooperados, demonstram as fragilidades que muitas cooperativas precisam superar.

Sobre a formação relacionada ao trabalho, 70,4\% (19) dos participantes afirmaram que não possuíam nenhum tipo de formação e 22,2\% (6) informaram que já fizeram curso de cooperativismo. Os cursos de capacitação em cooperativismo, economia solidária e em noções básicas de administração são essenciais para o bom desempenho das cooperativas de catadores, porém, a alta rotatividade dos catadores, observada nas cooperativas, dificulta a formação de trabalhadores capacitados (Magni e Günther, 2014). Nesse sentido, é necessário que as cooperativas, enquanto empreendimentos solidários, recebam apoio de outras instituições que possam colaborar para um projeto de educação permanente em economia solidária, sobretudo para o ingresso de novos membros, assim, buscando esclarecer direitos e deveres dos cooperados. Esse apoio pode partir de universidades no caráter de atividade de extensão.

A falta de formação se reflete na baixa capacidade administrativa e não implementação dos princípios da economia solidária, implicando em práticas que se desvirtuam das práticas de autogestão. Além disso, as cooperativas de catadores de materiais recicláveis enfrentam outras dificuldades, como a ausência de sistema de remuneração, instabilidade de renda, que varia de acordo com o material coletado e vendido, remuneração insuficiente para sobrevivência e pouca ou nenhuma ajuda dos governos locais (Castilhos Junior et al., 2013).

Ao considerar o trabalho de catador como uma atividade de inclusão social pela geração de renda e trabalho, é necessário que esses trabalhadores de fato sejam reconhecidos pela sociedade pelo seu papel ambiental, pois, muitas vezes, esse trabalho apenas garante a sobrevivência em condições desumanas (Miura e Sawaia, 2013). Portanto, as cooperativas de catadores que adotam o modelo de economia solidária assumem o papel de luta em prol do resgate da cidadania. Porém, o sucesso desses empreendimentos econômicos solidários também depende de políticas públicas, envolvimento da sociedade civil e acadêmica, e de fontes institucionais de financiamento.

\section{Conclusões}

As cooperativas de catadores de materiais recicláveis possuem perfis heterogêneos em decorrência de processos de formação e contextos regionais próprios. Enquanto empreendimentos de economia solidária apresentam algumas características de 
autogestão e possuem potencial em gerar trabalho e renda, além de lutar em prol da cidadania de seus colaboradores e na diminuição da desigualdade social. Porém, enfrentam grande dificuldade em adotarem, em suas rotinas, práticas fundamentais para uma administração democrática e igualitária.

Este estudo demonstrou que há uma larga lacuna entre os princípios e as práticas da autogestão, evidenciado pelo desconhecimento dos catadores sobre temas administrativos e financeiros internos, assim como o distanciamento das tomadas de decisão na cooperativa. Essa baixa participação está associada à divisão do trabalho na cooperativa entre gestão e processo de produção, sem o envolvimento entre as partes. Ainda pode ser identificado a falta de formação dos catadores para atuar na administração e em uma organização que destoa do modelo organizacional de empresas capitalistas tradicionais. Como consequência, há uma grande insatisfação entre os catadores quanto à organização da cooperativa, que pode afetar a motivação e a produtividade.

A partir dos dados coletados, infere-se que os catadores entendem que uma melhor renda depende do compromisso de cada um em cumprir suas atividades na cooperativa, uma vez que pertence a todos cooperados, sem distinções, ainda que nem todos compartilhem do mesmo pensamento.

As cooperativas precisam fortalecer a cultura da autogestão e promover a participação e capacitação de seus membros, além de desenvolver conexões com outras cooperativas e setores para se fortalecer e fazer frente à competitividade das empresas capitalistas dentro da cadeia de reciclagem, sem se confundirem com as práticas adotadas por essas empresas. Além disso, também apresentam o desafio de superar a própria dificuldade dos catadores em assimilar e aceitar os valores da economia solidária e autogestão em detrimento dos valores do sistema econômico dominante.

Desta maneira, algumas ações podem ser tomadas a fim de colaborar para o aprimoramento da atuação dos catadores: a) estabelecimento de vínculos entres cooperativas de catadores e universidades por meio de projetos de extensão para uma educação permanente em economia solidária e temas administrativos, financeiros, jurídicos, em gestão de pessoas, resíduos sólidos e saúde do trabalhador; b) fortalecimento da comunicação interna por meio de reuniões semanais para repasses sobre 0 desempenho da cooperativa; c) desenvolvimento de uma cultura de participação na tomada de decisão; d) organização das cooperativas em rede para compartilhamento de experiências de sucesso e boas práticas.

Portanto, as cooperativas de catadores, quando comprometidas com práticas de autogestão, são exemplos de possibilidades de se gerar renda e trabalho, mas, quando desvirtuadas de seus princípios correm o risco de se tornarem outra forma de exploração aos catadores. Contudo, o desafio do êxito das cooperativas não pode estar entregue apenas às mãos dos catadores, mas deve ser compartilhado com o governo local e a sociedade civil. Os municípios devem estabelecer contrato com cooperativas para pagamento do serviço de coleta e triagem de material reciclável, investir em infraestrutura e capacitação para os cooperados, além de políticas que assegurem os direitos sociais e vida digna para os catadores e suas famílias.

\section{Conflito de interesses}

Os autores declaram não haver conflito de interesses.

\section{Referências}

ABRELPE - Associação Brasileira de Empresas de Limpeza Pública e Resíduos Especiais. Panorama dos resíduos sólidos no Brasil. São Paulo: ABRELPE, 2020. 
Almeida, J. R.; Elias, E. T.; Magalhães, M. A.; Vieira, A. J. D. Efeito da idade sobre a qualidade de vida e saúde dos catadores de materiais recicláveis de uma associação em Governador Valadares, Minas Gerais, Brasil. Ciência \& Saúde Coletiva, v. 14, n. 6, p. 2169-2179, 2010. https://doi.org/10.1590/S1413-81232009000600024

Alves, K. A. N.; Costa, A. K. A. N.; Ramos, J. S. A.; Silva, D. M.; Rodrigues, F. M. Condições socioeconômicas, de saúde e hábitos de vida dos catadores de material reciclável. Saúde e

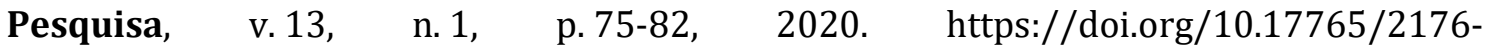
9206.2020v13n1p75-82

Arantes, B. 0.; Borges, L. D. O. Catadores de materiais recicláveis: cadeia produtiva e precariedade. Arquivos Brasileiros de Psicologia, v. 65, n. 3, p. 319-337, 2013.

Araújo, N. C. K.; Sato, T. O. A descriptive study of work ability and health problems among Brazilian recyclable waste pickers. Journal of Community Health, v. 43, n. 2, p. 366-371, 2018. https://doi.org/10.1007/s10900-017-0432-6

Asante, B. O.; Trask, C.; Adebayo, 0.; Bath, B. Prevalence and risk factors of low back disorders among waste collection workers: A systematic review. Work, v. 64, n. 1, p. 33-42, 2019. https://doi.org/10.3233/WOR-192977

Auler, F.; Nakashima, A. T. A.; Cuman, R. K. N. Health conditions of recyclable waste pickers. Journal of Community Health, v. 39, n. 1, p. 17-22, 2014. https://doi.org/10.1007/ s10900-013-9734-5

Bispo, C. S. Gerenciamento de resíduos sólidos recicláveis: estudo de caso das cooperativas do Município de Natal/RN. Natal: Universidade Federal do Rio Grande do Norte, 2013. (Dissertação de mestrado).

Brasil. Lei no 12.305, de 2 de agosto de 2010. Institui a Política Nacional de Resíduos Sólidos; altera a Lei no 9.605, de 12 de fevereiro de 1998; e dá outras providências. Disponível em: <http://www.planalto.gov.br/ccivil_03/_ato2007-2010/2010/lei/l12305. htm>. Acesso em: 10 maio 2021.

Campos, H. K. T. Recycling in Brazil: Challenges and prospects. Resources, Conservation and Recycling, v. 85, p. 130-138, 2014. https://doi.org/10.1016/j.resconrec.2013.10.017

Castilhos Junior, A. B.; Ramos, N. F.; Alves, C. M.; Forcellini, F. A.; Graciolli, O. D. Catadores de materiais recicláveis: análise das condições de trabalho e infraestrutura operacional no Sul, Sudeste e Nordeste do Brasil. Ciência \& Saúde Coletiva, v. 18, n. 11, p. 3115-3124, 2013. https://doi.org/10.1590/S1413-81232013001100002

CEMPRE - Compromisso Empresarial para Reciclagem. Review 2019. São Paulo: CEMPRE, 2019.

Coelho, A. P. F.; Beck, C. L. C.; Fernandes, M. N. S.; Freitas, N. Q.; Prestes, F. C.; Tonel, J. Z. Mulheres catadoras de materiais recicláveis: condições de vida, trabalho e saúde. Revista Gaúcha de Enfermagem, v. 37, n. 3, p. 1-8, 2016. https://doi.org/10.1590/19831447.2016.03.57321

Coelho, A. P. F.; Beck, C. L. C.; Silva, R. M.; Prestes, F. C.; Camponogara, S.; Peserico, A. Satisfaction and dissatisfaction in the work of recyclable solid waste segregators: Convergent-care research. Revista Brasileira de Enfermagem, v. 70, n. 2, p. 384-391, 2017. https://doi.org/10.1590/0034-7167-2016-0325

Coelho, A. P. F.; Beck, C. L. C.; Silva, R. M.; Vedootto, D. O.; Peserico, A; Silva, J. R. P. Conditions of work of solid waste collectors: Challenges and perspectives for a safe work. Revista Mineira de Enfermagem, v. 22, p. 1-8, 2018. https://doi.org/10.5935/14152762.20180057 
Cruvinel, V. R. N.; Marques, C. P.; Cardoso, V.; Novaes, M. R. C. G.; Araújo, W. N.; AnguloTuesta, A.; Escalda, P. M. F.; Galato, D.; Brito, P.; Silva, E. N. Health conditions and occupational risks in a novel group: Waste pickers in the largest open garbage dump in Latin America. BMC Public Health, v. 19, n. 1, p. 1-15, 2019. https://doi.org/10.1186/ s12889-019-6879-x

Demajorovic, J.; Caires, E. F.; Gonçalves, L. N. S.; Silva, M. J. C. Integrando empresas e cooperativas de catadores em fluxos reversos de resíduos sólidos pós-consumo: o caso Vira-Lata. Cadernos EBAPE.BR, v. 12, n. spe, p. 513-532, 2014. https://doi.org/10.1590/ 1679-39519020

Dias, B. C. C.; Cherfên, V. P. R. F.; Raupp, L. M.; Milnitisky-Sapiro, C. Representações sociais de papeleiros acerca do trabalho e moradia: o caso da Vila Chocolatão. Psicologia \& Sociedade, v. 26 , n. spe, p. 193-200, 2014. https://doi.org/10.1590/S010271822014000500020

Dias, S. M. Waste pickers and cities. Environment and Urbanization, v. 28, n. 2, p. 375390, 2016. https://doi.org/10.1177/0956247816657302

Dutra, R. M. S.; Yamane, L. H.; Siman, R. R. Influence of the expansion of the selective collection in the sorting infrastructure of waste pickers' organizations: A case study of 16 Brazilian cities. Waste Management, v. 77, p.50-58, 2018. https://doi.org/10.1016/ j.wasman.2018.05.009

Faria, J. H. Autogestão, economia solidária e organização coletivista de produção associada: em direção ao rigor conceitual. Cadernos EBAPE.BR, v. 15, n. 3, p. 629-650, 2017. https://doi.org/10.1590/1679-395157778

Fidelis, R.; Colmenero, J. C. Evaluating the performance of recycling cooperatives in their operational activities in the recycling chain. Resources, Conservation and Recycling, v. 130, p. 152-163, 2018. https://doi.org/10.1016/j.resconrec.2017.12.002

Guimarães, J. P. S. Socioeconomic profile of recyclable waste pickers organized in cooperatives and associations of the Espírito Santo. Vitória: Universidade Federal do Espírito Santo, 2017. (Dissertação de mestrado).

Gutberlet, J.; Carenzo, S.; Kain, J. H.; Azevedo, A. M. M. Waste picker organizations and their contribution to the circular economy: Two case studies from a Global South Perspective. Resources, v. 6, n. 4, 2017. https://doi.org/10.3390/resources6040052

IBGE - Instituto Brasileiro de Geografia e Estatística. Pesquisa Nacional de Saneamento Básico. Rio de Janeiro: IBGE, 2010.

IPEA - Instituto de Pesquisa Econômica Aplicada. Pesquisa sobre pagamento por serviços ambientais urbanos para gestão de resíduos sólidos. Brasília: IPEA, 2010.

IPEA - Instituto de Pesquisa Econômica Aplicada. Diagnóstico sobre catadores de resíduos sólidos. Brasília: IPEA, 2012.

IPEA - Instituto de Pesquisa Econômica Aplicada. Situação social das catadoras e dos catadores de material reciclável e reutilizável. Brasília: IPEA, 2013.

Lima, J. C. Participação, empreendedorismo e autogestão: uma nova cultura do trabalho? Sociologias, $\quad$ n. $25, \quad$ p. 158-198, 2010. https://doi.org/10.1590/S151745222010000300007

Lordello, J. Resíduos de decisão e suas repercussões à saúde dos trabalhadores em uma cooperativa de reciclagem. Cadernos de Psicologia Social do Trabalho, v. 17, n. 1, p. 116, 2014. https://doi.org/10.11606/issn.1981-0490.v17i1p1-16 
Magni, A. A. C.; Günther, W. M. R. Cooperativas de catadores de materiais recicláveis como alternativa à exclusão social e sua relação com a população de rua. Saúde e Sociedade, v. 23, n. 1, p. 99-109, 2014. https://doi.org/10.1590/S0104-12902014000100011

Medeiros, L. F. R. DE; Macêdo, K. B. Catador de material reciclável: uma profissão para além da sobrevivência? Psicologia \& Sociedade, v. 18, n. 2, p. 62-71, 2006. https://doi.org/10.1590/S0102-71822006000200009

Miura, P. O.; Sawaia, B. B. Tornar-se catador: sofrimento ético-político e potência de ação. Psicologia \& Sociedade, v. 25, n. 2, p. 331-341, 2013.

Moreira, A. M. M.; Günther, W. M. R.; Siqueira, C. E. G. Workers' perception of hazards on recycling sorting facilities in São Paulo, Brazil. Ciência \& Saúde Coletiva, v. 24, n. 3, p. 771-780, 2019. https://doi.org/10.1590/1413-81232018243.01852017

Navarrete-Hernandez, P.; Navarrete-Hernandez, N. Unleashing waste-pickers' potential: Supporting recycling cooperatives in Santiago de Chile. World Development, v. 101, p. 293-310, 2018. https://doi.org/10.1016/j.worlddev.2017.08.016

Petersen, F.; Souza, T. G.; Lopes, A. A. Relações entre autogestão e cidadania: o papel da participação em uma cooperativa na construção da identidade de cidadão. Psicologia \& Sociedade, $\quad$ v. 26 , $\quad$ n. $2, \quad$ p. $483-495,2014$. https://doi.org/10.1590/S010271822014000200024

Porto, M. F. D. S.; Juncá, D. C. D. M.; Gonçalves, R. D. S.; Filhote, M. I. D. F. Lixo, trabalho e saúde: um estudo de caso com catadores em um aterro metropolitano no Rio de Janeiro, Brasil. Cadernos de Saúde Pública, v. 20, n. 6, p. 1503-1514, 2004. https://doi.org/ 10.1590/S0102-311X2004000600007

Queiroz, D. T.; Vall, J.; Souza, Â. M. A. E.; Vieira, N. F. C. Observação participante na pesquisa qualitativa: conceitos e aplicações na área da saúde. Revista Enfermagem UERJ, v. 15, n. 2, p. 276-283, 2007.

Santos, C. V.; Zanin, M.; Teixeira, B. A. D. N. Fóruns comunitários como estratégia para controle social de políticas públicas para gestão de resíduos sólidos: o caso de São Carlos, São Paulo, Brasil. In: Leal, A. C.; Zanin, M.; Dias, L. S. (Orgs.). Resíduos sólidos urbanos: aproximação ao tema em cidade de Cuba e Brasil. 1. ed. Tupã: ANAP, 2018. p. 77-89.

Savio, A.; Teixeira, B. A. D. N. Descrição e análise do processo de formação de uma rede de cooperativas de catadores de materiais recicláveis: caso da Rede Anastácia, Estado de São Paulo. Revista Nacional de Gerenciamento de Cidades, v. 4, n. 24, p. 57-72, 2016. https://doi.org/10.17271/2318847242420161324

Singer, P. Introdução à Economia Solidária. 1. ed. São Paulo: Fundação Perseu Abramo, 2002.

Singh, J.; Laurenti, R.; Sinha, R.; Frostell, B. Progress and challenges to the global waste management system. Waste Management \& Research, v. 32, n. 9, p. 800-812, 2014. https://doi.org/10.1177/0734242x14537868

Souza, R. L. R.; Fontes, A. R. M.; Salomão, S. A triagem de materiais recicláveis e as variabilidades inerentes ao processo: estudo de caso em uma cooperativa. Ciência \& Saúde Coletiva, v. 19, n. 10 , p. 4185-4195, 2014. https://doi.org/10.1590/1413812320141910.09072014

Sterchile, S. P. W.; Batista, A. O espaço da cooperativa "amigos do meio ambiente": cooperativa de trabalho ou cooperfraude? Serviço Social \& Sociedade, n. 106, p. 314-334, 2011. https://doi.org/10.1590/S0101-66282011000200007 
Tauile, J. R.; Rodrigues, H. Economia solidária e autogestão: a criação e recriação de trabalho e renda. Boletim Mercado de Trabalho, v. 9, n. 24, p. 35-43, 2004.

Teixeira, K. M. D. Work and perspectives according to the perception of recycled garbage pickers. Psicologia \& Sociedade, v. 27, n. 1, p. 98-105, 2015. https://doi.org/10.1590/ 1807-03102015v27n1p098

Yang, H.; Ma, M.; Thompson, J. R.; Flower, R. J. Waste management, informal recycling, environmental pollution and public health. Journal of Epidemiology and Community Health, v. 72, n. 3, p. 237-243, 2018. https://doi.org/10.1136/jech-2016-208597 